\title{
A RELAÇÃO DO FUTSAL COM AS LESÕES NOS MEMBROS INFERIORES
}

DOI: 10.48140/digitaleditora.2020.002.12

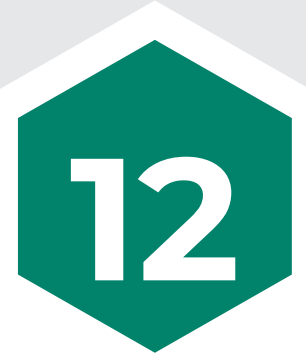

RESUMO

Objetivos: Dessa maneira, o presente trabalho tem como objetivo analisar por meio de uma revisão bibliográfica a relação das lesões nos membros inferiores do futsal.

Métodos: Trata-se de um estudo de pesquisa de caráter descritivo com análise quantitativa e qualitativa, realizado por meio de pesquisa bibliográfica, através de revisão de literatura, por meio de livros, periódicos de bases de pesquisa - Scielo, Efdeportes, entre outros - monografias e teses e web sites; com literatura datada desde o ano de 1987 até os dias atuais. Trata-se de um estudo de revisão integrativa, que visa destacar os principais motivos que ocasionam as lesões na prática do futsal.

Resultados: Estudos mostraram que vários fatores podem ser decisivos para o grande número de ocorrências de lesões nos membros inferiores e que atitudes corretas e imediatas podem favorecer a recuperação do atleta de forma mais rápida.

Conclusão: Evidenciou-se que, um treinamento correto, bem planejado e estruturado, entre o profissional e o atleta garante um trabalho eficiente, minimizando o número de lesões, principalmente na fase inicial de aprendizagem.

\section{S}

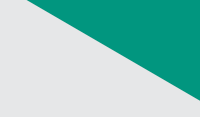

(19)

(1)

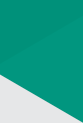

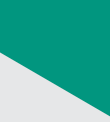

. 


\section{THE RELATIONSHIP OF FUTSAL WITH INJURIES IN LOWER MEMBERS}

DOI: 10.48140/digitaleditora.2020.002.12

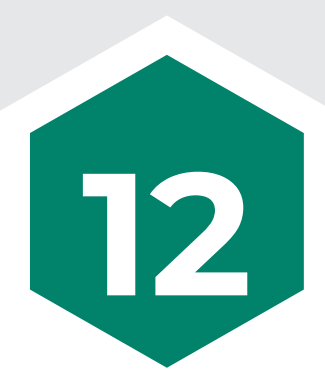

\section{ABSTRACT}

Recebido em: $10 / 12 / 2020$

Aprovado em: 28/12/2020

Conflito de Interesse: não

Suporte Financeiro: não houve
Objectives: In this way, the present study aims to analyze, through a bibliographic review, the relationship of injuries in the lower limbs of futsal.

Methods: This is a descriptive research study with quantitative and qualitative analysis, carried out through bibliographic research, through literature review, through books, journals of research bases - Scielo, Efdeportes, among others-monographs and theses and web sites; with literature dated from 1987 to the present day. This is an integrative review study, which aims to highlight the main reasons that cause injuries in futsal practice.

Results: Studies have shown that several factors can be decisive for the large number of injuries occurring in the lower limbs and that correct and immediate attitudes can favor the athlete's recovery more quickly.

Conclusion: It was evidenced that, a correct, well planned and structured training, between the professional and the athlete guarantees an efficient work, minimizing the number of injuries, mainly in the initial learning phase. 


\section{(8) \\ INTRODUÇÃO}

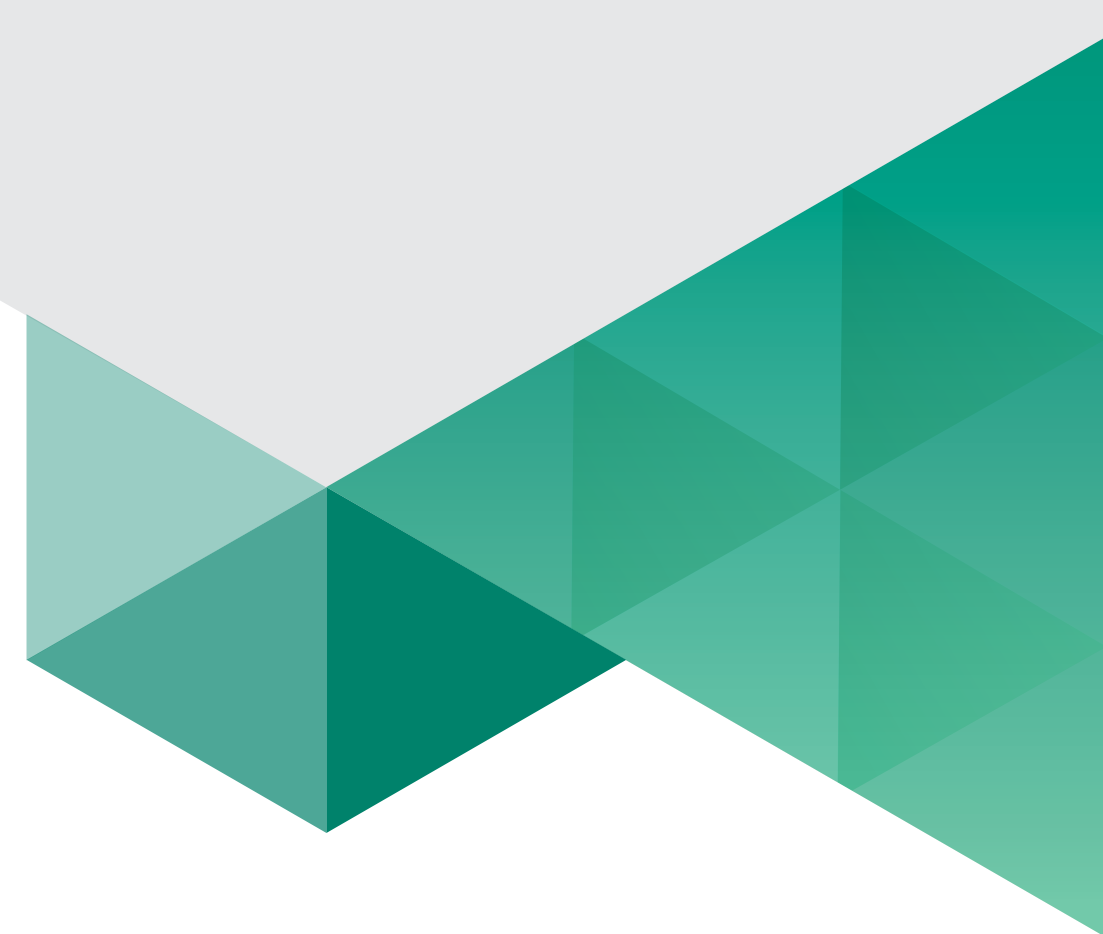

O mundo esportivo vem passando por diversos processos de evolução, visando a tendência para o profissionalismo e com isso o interesse pelo futsal vem aumentando cada vez mais por crianças, jovens e adultos e assim aumentando a incidência de lesões tanto no futsal profissional como no futsal amador.

Segundo Alonso et al. (2003), o futebol, assim como outros esportes, promove a especialização dos atletas para desempenhar as funções táticas, específicas e solicitação muscular seletiva. O futsal é um esporte que requer bastante esforço da musculatura dos membros inferiores. Diferentes formas de deslocamentos, velocidades e intensidades são realizadas dentro do jogo de futsal e entre as diferentes funções de cada jogador em quadra, os quais predispõem as articulações dos membros inferiores. Na prática desse esporte alguns grupos musculares são mais exigidos que outros, isso pode gerar desequilíbrio entre o membro dominante e não-dominante e/ou entre grupos musculares agonistas/ antagonistas do mesmo membro. Essas demandas funcionais específicas dos membros inferiores podem determinar o surgimento de lesão no futsal. Além disso, lesões determinam alterações estruturais e funcionais em grupos musculares que agem sobre uma determinada articulação.

Nessa perspectiva o futsal vem ganhando uma nova roupagem que seria a força, ocasionando níveis de estresse físico e mental, influenciando de forma negativa no bem estar, na saúde, qualidade de vida e o futuro desses atletas e consequentemente na alta incidência de lesões.

O futsal é um esporte cada vez mais praticado no mundo e é um dos mais populares do Brasil (COSTA, 2005). Contudo ainda se apresenta como uma modalidade com características pouco definidas. As lesões dessa prática estão aumentando e juntamente com elas a preocupação em preveni-las.

Portanto, é fundamental que o profissional de Educação Física tenha uma formação que lhe capacite a preparar aulas e treinamentos adequados a seus alunos.

Para afastar ao máximo a probabilidade de ocorrerem acidentes e para que o profissional de educação física possa atender adequadamente às necessidades e aos interesses de seus alunos, é necessário um conhecimento preciso do indivíduo e do esporte em questão. O esperado é que os profissionais encontrem, na formação de qualquer grupo, variações individuais quanto aos aspectos fisiológicos, psicológicos e culturais que justifiquem uma atitude personalizada na proposição de esforços físicos (FRONTERA, DAWSON e SLOVIK, 2001). 
Os profissionais de educação física devem estar habilitados para oferecer aos seus atletas este atendimento, pois desta maneira evitarão possíveis acidentes e o treinamento atingirá melhores resultados.

Considerando essa realidade, o objetivo da realização da presente pesquisa é analisar a relação do futsal com as lesões dos membros inferiores enfatizando a importância da assistência especializada de primeiros socorros, ficando evidente a importância do estudo das lesões no esporte, dando ênfase nas medidas preventivas e no tratamento precoce, que consequentemente melhora a qualidade de vida e desempenho do atleta.

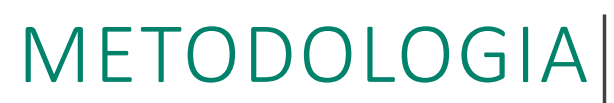

O presente trabalho foi realizado a partir do método de pesquisa de caráter descritivo com análise quantitativa e qualitativa, por pesquisa bibliográfica, através de revisão de literatura, por meio de livros, periódicos de bases de pesquisa - Scielo, Efdeportes, entre outros - monografias e teses e web sites; com literatura datada desde o ano de 1987 até os dias atuais. Trata-se de um estudo de revisão bibliográfica, que visa destacar os principais motivos que ocasionam as lesões na pratica do futsal.

A pesquisa bibliográfica, ou de fontes secundárias, abrange toda a bibliografia já tornada pública em relação ao tema de estudo, desde publicações avulsas, boletins, jornais, revistas, livros, pesquisas, monografias, teses, material cartográfico, entre outros, até meios de comunicações orais: rádio, gravação em fita magnética e audiovisuais; filmes e televisões. "Sua finalidade é de colocar o pesquisador em contato direto com tudo o que foi escrito, dito ou filmado sobre determinado assunto, inclusive conferências seguidas de debates que tenham sido transcritos por alguma forma, querem publicadas, quer gravadas". (MARCONI; LAKATOS, 1990, p.66).

A pesquisa pode ter ainda um caráter exploratório por estar aprofundando o assunto que poder ter ficado superficialmente entendido pelo pesquisador. Para Raupp e Beuren (2006, p. 80) [...] pesquisa exploratória é desenvolvida no sentido de proporcionar uma visão geral acerca de conceitos preliminares sobre determinada temática não contemplada de modo satisfatório anteriormente. Assim, contribui para o esclarecimento das questões superficialmente abordadas sobre o assunto.

Assim, a bibliografia fornece meios para definir, resolver tantos problemas já conhecidos como também explorar novas áreas onde os problemas não foram resolvidos suficientemente, tendo por objetivo permitir ao acadêmico um reforço paralelo em suas pesquisas ou manipulação de suas informações. 


\section{RESULTADOS E DISCUSSÃO}

O crescimento da prática do futsal está filiado fundamentalmente aos aspectos táticos, técnicos e físicos, exigindo resultados, cada vez melhores do atleta. Dessa forma, com o aumento de campeonatos aumenta a tendência das equipes praticarem mais para se adaptar a isso, o atleta é imposto mais fisicamente, o que gera uma carga excessiva de exercício sendo capaz de estimular a curto, médio ou em longo prazo, traumas de diferentes graus no aparelho musculoesquelético, adicionando o perigo para lesões.

Sabemos que o futsal é um esporte que possui como características a presença de movimentos bruscos, grande contato, e o grande número de jogos realizados pelos atletas, facilitam a ocorrência de lesões. E estas lesões causam desconforto e incômodo nos atletas em toda sua carreira artística e até mesmo a interrupção precoce desta; são contusões, entorses, luxações, fraturas, tendinites, distensões, rupturas de ligamentos, entre outras. E os números de horas de treino e competições são vistos como alguns dos principais fatores que contribuem para o surgimento de lesões em seus praticantes.

Segundo Cohen e Abdalla (2003) a incidência de lesões varia de 10 a 35 por cada 1000 horas de jogo, acreditando-se que um jogador pratica em média 100 horas de jogo por ano, estimando-se que cada atleta tenha pelo menos uma lesão por ano. Com o crescente número de jogos realizados pelas equipes, tem-se verificado diminuição do período preparatório para as principais competições, o que de certa forma obriga os preparadores físicos a trabalhar com maior racionalização do tempo e especificidade possíveis (VALQUER; BARROS apud BARROS e GUERRA, 2004).

Desta forma o profissional de Educação Física responsável pela preparação física dos atletas deve saber montar os treinos conforme os calendários e sugerir ao técnico da equipe a quantidade de carga de jogos e treinamento para os respectivos atletas, além disso, o acompanhamento médico é de extrema importância para que o técnico não utilize jogadores que não estão em condições clínicas e físicas para a realização de jogos evitando assim contratempos e prejuízo na vida dos atletas.

Segundo Fernandes (1994) o objetivo de qualquer atleta é alcançar o máximo rendimento individual possível durante as competições e o treinador, com o amplo conhecimento teórico que deve possuir apoiado em resultados científicos e técnicos e em sua variada experiência prática, prepara o caminho para o atleta e sua equipe atingirem as suas metas através do desenvolvimento do rendimento. A ocorrência de lesões pode estar diretamente relacionada a esta busca de rendimento máximo, e também das falhas que poderão ocorrer durante este processo; o inicio cada vez mais precoce das atividades competitivas, o aumento da carga de treinamentos e da frequência de jogos, a não utilização de material adequado, o mau preparo físico, são exemplos de fatores que podem contribuir pra a 
ocorrência de lesões. É importante ressaltar que as lesões também podem ocorrer de maneira inesperada e não intencional, ou mesmo, fora do ambiente de treinos e jogos dos jogadores.

Infelizmente, muitas vezes as lesões provocam diminuição no rendimento ou inclusive obrigam a uma retirada precoce da prática desportiva. Em algumas situações, as lesões esportivas ocorrem como consequência de um acidente, práticas incorretas de treinamento ou falta de condição física adequada. Adicionalmente, não realizar o aquecimento ou não alongar o suficiente antes de um jogo ou exercício pode também causar uma lesão. As lesões podem também ocorrer devido a determinadas alterações estruturais do corpo, que podem causar maior estiramento em algumas partes do que em outras. Podem também ser consequência do enfraquecimento dos músculos, tendões ou ligamentos. O desgaste crônico é a causa da maioria dessas lesões, quando os movimentos repetitivos afetam os tecidos suscetíveis (GRISOGONO, 1989).

Técnicas incorretas de treinamento são a principal causa de lesões dos músculos ou articulações. Em geral, a pessoa não se recupera de forma adequada após um período de treinamento ou não interrompe o exercício de imediato quando ocorre a dor. São necessários mais que dois dias para que as fibras musculares prejudicadas se curem e substituam o glicogênio após o exercício intenso. As lesões esportivas mais comuns são: Distensões; Lesões nos joelhos; Inchaço muscular; Lesões no tendão de Aquiles; Dor na tíbia; Fraturas; Deslocamento (RODRIGUES, 1994).

Outros fatores psicológicos que contribuem para o desenvolvimento dessas lesões nos atletas estão relacionados à falta de profissionais para orientações técnicas, alimentação não adequada, ao tempo insuficiente de descanso para o corpo, aliado ao consumo de bebidas alcoólicas. Tais fatores justificam o alto índice de jogadores que já sofreram algum tipo de lesão ou encontram-se lesionados no futsal e com graus de complexidade.

Temos também as variações da idade e do sexo, onde são atribuídas basicamente ao estado de saúde, aos hábitos de vida e também das experiências quanto à prática de exercícios físicos e consequentemente, os níveis de aptidão física. Essas variações individuais são muito importantes, pois é mediante a rotina de avaliação das reais condições individuais que se torna fundamental na determinação do potencial de cada um.

Segundo Guedes e Guedes (1995, p.78):

A falta de avaliação prévia que venha a subsidiar as decisões na elaboração dos programas de exercícios físicos pode ocasionar o estabelecimento de esforços físicos não adequados, levando ao desencorajamento para participar das atividades programadas. Prescrições incorretas também podem levar a desgastes funcionais e orgânicos indevidos, induzindo à fadiga psicológica e física excessivas, a graves lesões ortopédicas e ao risco de precipitação de acidentes cardiovasculares.

Ciente da importância do profissional de Educação Física na promoção da saúde, o Ministério da Saúde incluiu a atividade física no Sistema Único de Saúde (SUS). As atividades são vistas como um importante elemento para desenvolver a qualidade de vida na população. Clínicas, academias e centros de reabilitação física passaram a funcionar com a figura do profissional de Educação Física.

Portanto, a inexistência de um condicionamento físico apropriado e a prática errada de algumas atividades físicas, ou seja, praticá-las sem o acompanhamento de um Profissional de Educação Física, estão entre as razões mais comuns que levam o indivíduo a se lesionar.

A generalidade dos estudos indica que as lesões no Futsal acontecem predominantemente nos membros inferiores, o que encontra justificação nas características da própria modalidade (SERRANO, 
SHAHIDIAN, VOSER \& LEITE,2013). Junge \& Dvorak, (2010), Kurata et al., (2007), e Raymundo et al., (2005), obtiveram valores de $70 \%, 88,1 \%$ e $88,2 \%$, respetivamente, para a porcentagem de incidência de lesões nos membros inferiores durante a prática de Futsal.

Gaether (2012) afirma que "o corpo do atleta de alto nível acaba sendo usado de forma mecânica, e o prazer de jogar muitas vezes é substituído pela necessidade dos resultados impostos pela torcida". Dessa forma, observa-se que os atletas estão focados apenas no resultado positivo, mesmo que a carga excessiva de esforço físico nos jogos e nos treinamentos venham a prejudica-los. Da mesma forma, os atletas amadores querem buscar a mesma intensidade dos jogadores profissionais, mas por falta de orientação inadequada e preparação física muito abaixo do ideal vêm sofrendo com frequência lesões consideradas graves.

Para a adequada prevenção de lesões é importante considerar também as condições ambientais tais como altas e baixas temperaturas, pois estes fatores são relevantes quando se fala de lesões em atletas principalmente em treinos e competições. Se o ganho de calor ultrapassa sua perda, como pode ocorrer prontamente durante um exercício vigoroso em um meio ambiente quente, a temperatura central sobe; em um meio ambiente frio, por outro lado, a perda de calor costuma ultrapassar sua produção, e a temperatura central cai (MCARDLE; KATCH; KATCH, 1998, p. 475).

Considerando os exercícios sob altas temperaturas encontramos que a elevação na temperatura ambiente reduz o gradiente térmico entre o meio ambiente e a superfície da pele e entre esta superfície e o centro do corpo. Isso tudo se opõe à perda de calor pelo corpo. Na verdade, pode haver ganho de calor quando a temperatura do meio ambiente é mais alta que a temperatura da pele. Pela mesma razão, o aumento da umidade representa uma barreira para a perda de calor pelo mecanismo de evaporação. Durante o exercício prolongado em um ambiente aquecido, estas barreiras para a perda de calor podem dar origem a um aumento excessivo da temperatura retal e limitar profundamente a capacidade de 0 indivíduo realizar algum trabalho em uma temperatura elevada (FOSS e KETEYIAN, 1998, p.470). O estresse pelo calor não é refletido de maneira precisa pela temperatura do ar isoladamente. A umidade, a velocidade do ar (ou vento) e a radiação térmica também contribuem para o estresse total pelo calor que você experimenta ao exercitar-se no calor (WILMORE e COSTILL, 2001, p. 324).

Assim como as altas temperaturas podem prejudicar o desenvolvimento as baixas temperaturas também ocasionam riscos à saúde dos atletas, pois o frio altera tanto o fisiológico quanto o comportamental dos atletas.

As lesões mais comuns relacionadas ao futebol são: distensões dos tornozelos, distensões dos músculos da perna, fraturas, lesões do joelho e cabeça (MANUAL MERK, 2008). Segundo Rodrigues (1994) em média $80 \%$ a $90 \%$ das lesões em atletas de futebol, localizam-se nos membros inferiores. A seguir são citadas com sucinta explicação estas lesões mais comuns no futsal:

\section{DISTENSÕES MUSCULARES}

São pré-dispostas por uma distonia muscular aguda, um aumento repentino, imprevisto e brutal da tensão no músculo ou parte dele, durante o esforço, e superior à capacidade de resistência (RODRIGUES, 1994).

Podem ser causadas por: Movimento para estender um músculo na direção contrária ao mesmo; Contração forte de um músculo contra uma resistência; Contração forte de um músculo quando não está pronto. No futebol, as distensões musculares mais comuns são as da virilha, panturrilha e quadríceps. Essas lesões podem ser dolorosas e deixar o jogador fora de campo por diversos dias ou semanas. As lesões relacionadas ao futebol ocorrem frequentemente devido à parada constante e movimentos de arranque ou por dar um passo maior do que o músculo pode suportar (MANUAL MERK, 2008). 


\section{DISTENSÕES}

Lesões nos tornozelos, na parte inferior de uma perna e nos joelhos (em geral distensões) são as lesões mais frequentes relacionadas ao futebol. Depois da distensão do tornozelo, as mais comuns são as distensões do joelho do ligamento colateral medial. Os movimentos laterais e os giros durante o futebol contribuem para essas lesões (MANUAL MERK, 2008).

\section{FRATURAS}

Fratura pode ser considerada uma interrupção completa na continuidade de um osso ou um a interrupção ou rachadura parcial. Estas podem ser subdivididas, de acordo com sua etiologia, em três grupos: 1) fraturas causadas exclusivamente por traumas; 2) fraturas de fadiga ou estresse; e 3) fraturas patológicas (ADAMS; HAMBLEN, 1994).

A maioria das fraturas relacionadas ao futebol ocorre nas extremidades inferiores e geralmente resultam de um contato forte (MANUAL MERK, 2008).

\section{LESÕES DE JOELHO}

O joelho é muito propenso a lesões, por causa de sua mobilidade e da variedade de tensões a que submetemos. O tipo mais comum de lesão traumática do joelho é a torção, que acontece mais frequentemente quando ele está dobrado, sustentando o peso do corpo, e é inesperada ou desastradamente deslocado, os jogadores de futebol e os esquiadores são os mais suscetíveis a esse tipo de lesão. O joelho é vulnerável também a lesões por excesso de uso: dores provocadas por uma atividade, que se agravam progressivamente, se você mantém a atividade (GRISOGONO, 1989).

Esta é a lesão mais importante relacionada ao futebol. Os ligamentos colaterais mediais, os meniscos e os ligamentos principais são as partes do joelho em que mais comumente ocorrem essas lesões, neste tipo de esporte. Muitas lesões do joelho, especialmente a hérnia dos ligamentos principais ocorrem fora do contato físico. Em geral, elas ocorrem em função de um estresse excessivo em uma junta do joelho durante as paradas e arranques repentinos (MANUAL MERK, 2008).

É importante ressaltar que os primeiros socorros ou atendimento de urgência, são essências no caso de lesões ou acidentes de qualquer indivíduo comum, para o atleta, assume uma importância ainda maior, pois o atleta necessitará de uma rápida estabilização de suas funções. Estar familiarizado com as lesões (típicas) que ocorrem com maior frequência nas diversas modalidades esportivas, saber o que fazer para prestar socorro no momento certo, permite em alguns casos salvar uma vida, evitar o agravamento de lesões reduzindo o sofrimento do atleta, favorecendo assim o retorno precoce às atividades profissionais (MENESES, 1983, pág.57).

Os profissionais da área de educação física, devem estar bem preparados para prestar os primeiros socorros para seus atletas e, como a grande maioria das lesões em atletas são musculares e ligamentares, deve ocorrer a assistência médica imediata dos primeiros socorros. 


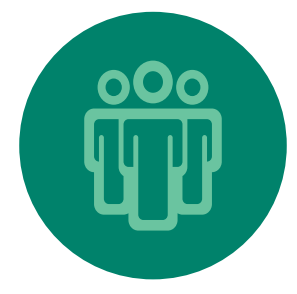

\section{CONCLUSÃO}

A presente investigação atingiu todos os objetivos a que se propôs desde o início, concluindo-se que vários fatores podem ser decisivos para o grande número de ocorrências de lesões. Por fim, pudemos observar através deste estudo que, um treinamento correto e bem planejado, são fatores muito importantes para evitar e reduzir o risco de lesões nos membros inferiores e demais.

Observamos durante o estudo que o joelho é o membro mais propenso a lesões, por causa de sua mobilidade e da variedade de tensões a que é submetido e que a utilização de recursos externos como a órteses, bandagem funcional, palmilhas de correção, taping e de tratamentos como os recursos proprioceptivos surgem como grandes ferramentas não só na reabilitação, mas como na prevenção de recidivas ou de novas lesões.

Pelas características do futsal, as lesões devem ter um tratamento rápido para que o jogador ou o praticante de futsal retome o mais rápido possível as suas atividades. Pode-se concluir também que a maior parte das lesões, ocorrem durante o jogo, devido o atleta se empenhar muito mais no jogo do que no treino.

Portanto, um trabalho integrado entre os envolvidos garante um trabalho eficiente, minimizando o número de lesões principalmente na fase inicial de aprendizagem. 


\section{REFERÊNCIAS}

ADAMS, John C; HAMBLEN, David L. Manual de fraturas: incluindo lesões articulares. Artes Medicas, 1994.

ALONSO, A. C.; GREVE, J. M. D.; MACEDO, O.G.; PEREIRA, C. A. M.; SOUSA. P.C.M. Avaliação isocinética dos inversores e eversores de tornozelos: estudo comparativo entre atletas de futebol e sedentários normais. Rev. Bras de Fisiot, v.7, n.3,2003.

BARROS, Turíbio Barros; GUERRA, Isabela. Ciência do Futebol. São Paulo: Manole, 2004.

COHEN, Moisés; ABDALLA, Rene Jorge. Lesões nos esportes. Rio de Janeiro, 2003.

COSTA, C.N. RETROSPECTIVO: PERFIL DE LESÕES NOS ATLETAS DA EQUIPE DE FUTSAL DA UNIMED EM 2005.Monografia apresentada ao curso de fisioterapia, com requisitos a obtenção do Título em Bacharel em Fisioterapia. Tubarão, 2005.

FERNANDES, José Luís. Futebol: ciência, arte ou sorte: Treinamento para profissionais: alto rendimento: preparação física, técnica, tática e avaliação. São Paulo: EPU, 1994.

FOSS, M.L.; KETEYAN, S. Bases Fisiológicas do Exercício e do Esporte. 4.ed. Rio de Janeiro: Guanabara Koogan, 1998.

FRONTERA, W.R; DAWSON, D.M; SLOVIK.D.M, Exercício físico e reabilitação. Porto Alegre: Artmed, 2001.

GAETHER, G. Psicologia somática aplicada ao esporte de alto rendimento. (Dissertação de mestrado, Universidade Federal de Santa Catarina). Florianópolis, 2012.

GUEDES.D. P; GUEDES, J, E.R.P. Exercício físico na promoção da saúde. Londrina Midiograf, 1995.

GRISOGONO, Vivian. Lesões no esporte. São Paulo: Martins Fonts, 1989.

JUNGE, Astrid; DVORAK, MD; GRAF-BAUMANN, Toni. Football injuries during the world cup 2002. The American Journal of Sports Medicine 32: 23s-27s (2004) American Orthopaedic for Sports Medicine.

MANUAL MERK. Lesões Esportivas. Disponível em www.msd-brasil.com.br, acessado em setembro de 2008.

MENESES, L.J.S. O esporte...Suas lesões. Rio de Janeiro, Printed, 1983.

MCARDLE, W. D.; KATCH, F. J.; KATCH, V. L. Fisiologia do exercício: energia, nutrição e desempenho humano. 4. ed. Rio de Janeiro: Guanabara Koogan, 1998 
RAYMUNDO JLP, RECKERS LJ, LOCKS R, SILVA L, HALLAL PC. (2005). Injury profile and physical capacity of professional soccer players during one season. Revista Brasileira de Ortopedia, 40:341-8.

RODRIGUES, Ademir. Lesões musculares e tendinosas no esporte. São Paulo: Cefespar, 1994.

SERRANO, J. M., SHAHIDIAN, S., VOSER, R. C. \& LEITE, N. (2013). Incidência e fatores de risco de lesões em Jogadores de Futsal Portugueses. Rev Bras Med Esporte. São Paulo, v.19 n. 2. 123-129. Março/abril.2013.

WILMORE, J.H.; COSTILL, D.L. Fisiologia do esporte e do exercício. $2^{\circ}$ ed. São Paulo: Manole, 2001. 